\title{
Enzymatic and Structural Characterization of Alanine Racemase from Enterococcus faecium by Kinetic and Computational Studies
}

\author{
Arie Van Wieren*, Emma Bouchard, \& Sudipta Majumdar \\ Madia Department of Chemistry, Indiana University of Pennsylvania, Indiana, PA \\ https:// doi.org/10.33697/ ajur.2020.039 \\ Students: arievanwieren23@gmail.com*fyjy@iup.edu \\ Mentor:smajum@iup.edu*
}

\begin{abstract}
The surge in vancomycin-resistant enterococci (VRE) strains poses a serious threat to public and clinical health. VRE strains are the leading cause of multi-drug resistant enterococcal infections and are commonly acquired from medical devices. Therefore, it is essential to discover new antibacterial targets and drugs for this pathogen. Alanine racemase could be a valuable drug target due to its crucial role in E. faecium survival. Alr from E. faecium (EF_Alr) was heterologously produced and purified from E. coli., and the steady-state kinetic constants were determined at different $\mathrm{pH}$ values. Using a coupled reaction with L-alanine dehydrogenase, rate of production of NADH was measured at $340 \mathrm{~nm}$ to observe EF_Alr activity in the D- to L-alanine direction. The highest catalytic efficiency, $8.61 \pm 0.5 \mathrm{~s}^{-1} \mathrm{mM}^{-1}$, was found at $\mathrm{pH}$ 9. Additionally, the tentative active site residues, Lys40 and Tyr268, for the alanine racemization reaction were assigned by homology modeling and sequence comparison studies. Using UCSF Chimera, the structure of the EF_Alr homology model was superimposed and compared to the crystal structure of Alr from E. faecalis.
\end{abstract}

\section{KEYWORDS}

Alanine Racemase; Enterococcus faecium; Vancomycin-Resistant Enterococci; Homology Modeling; pH Optimum; Kinetic Characterization; SWISS-MODEL Server; Steady-State Kinetics

\section{INTRODUCTION}

Vancomycin-resistant enterococci (VRE) strains have gained significant attention due to their high prevalence in hospital-acquired infections and resistance to vancomycin, a drug used to treat life-threatening gram-positive bacterial infections unresponsive to other antibiotics. ${ }^{1}$ Additionally, these enterococci possess intrinsic resistance to a myriad of other antibiotics and are noted for their ability to acquire resistance to all currently available antibiotics by way of mutation or by genetic transfer through plasmids and transposons. ${ }^{2}$ Enterococci can be responsible for multiple types of infections. These infections, notably endocarditis and bacteremia, can be life-threatening and often require specific treatments due to their multidrug-resistant properties. ${ }^{3}$ For these reasons, VRE have flourished in the hospital environment. In their recent report, the Centers for Disease Control and Prevention (CDC) categorized VRE as a "serious threat" and reported that VRE infections were responsible for an estimated 54,500 cases of infection in hospitalized patients each year in the United States. ${ }^{4}$

Enterococcus faecium is a Gram-positive VRE bacterium that has emerged in the last two decades as a leading cause of multidrugresistant enterococcal infections in the United States. Out of a large set of E. faecium clinical isolates 36.4\%, $77.3 \%$, and $90.1 \%$ of strains were found to be resistant to vancomycin, gentamicin, and streptomycin respectively. ${ }^{5}$ E. faecium infections, as with other VRE infections, have been found to pose serious threats in hospital environments. The National Healthcare Safety Network reported that the majority of device-associated infections (central lines, urinary drainage catheters, and ventilators) were due to either vancomycin- or ampicillin-resistant E. faecium. ${ }^{6}$ This situation is especially concerning in light of the COVID-19 pandemic, where ventilators and other medical devices were utilized on a large scale to treat immunocompromised patients. ${ }^{7}$ As of May 2020, there has been a report of co-infection of COVID-19 and E. faecium. ${ }^{8}$ Clearly, there is a need to explore novel antibiotic drug targets for this pathogen so that its impact on hospital-acquired infections and public health can be mitigated.

One such antibiotic drug target is alanine racemase (Alr), a pyridoxal 5'-phosphate (PLP)-dependent bacterial enzyme that functions to racemize L-alanine and D-alanine. This enzyme plays a vital role in bacterial cell wall synthesis as D-alanine is one of the principal components in the synthesis of peptidoglycan. ${ }^{9}$ Alr has long been considered an appealing target for drug development due to its prevalence in bacteria and its fundamental role in their survival. ${ }^{10-12}$ The Alrs from several different pathogens, including another VRE pathogen E. faecalis, have been structurally and kinetically characterized. ${ }^{13-20}$ However, no work has yet been published for the Alr from E. faecium (EF_Alr). In this paper, we report the cloning, expression, purification, and functional characterization of EF_Alr. Additionally, we propose the catalytic residues, Lys40 and Tyr268, for alanine racemization 
reaction using sequence comparison and homology modeling studies based on the crystal structure of Alr from E. faecalis. We anticipate that our report will pave the way for antibiotic drug development against this infectious human pathogen.

\section{METHODS AND PROCEDURES}

Chemicals and reagents utilized for this study were purchased from Sigma-Aldrich, Fisher, or Alfa Aesar and were of the highest chemical grade available. Kinetic measurements were made using buffers with $50 \mathrm{mM}$ sodium monobasic/dibasic phosphate, 100 $\mathrm{mM} \mathrm{NaCl}(\mathrm{pH} 6.5,7,7.5,8,8.5)$ and $50 \mathrm{mM}$ sodium carbonate/bicarbonate, $100 \mathrm{mM} \mathrm{NaCl}$ (pH 9, 9.5, 10). Multiskan GO (Fisher Scientific) was used to collect UV-vis Spectrophotometric data. Protein purifications were carried out using BioLogic DuoFlow (Bio-Rad) medium flow chromatography system. The genomic DNA of E. faecium TEX16 (ATCC BAA-472) was purchased from American Type Culture Collection (Rockville, MD). L-Alanine dehydrogenase used in this study was produced and purified as described previously. ${ }^{21}$

Sequence alignment

An initial analysis was completed to determine the maximum score and amino acid sequence identity between EF_Alr and the Alr from five other organisms by running a BLAST search. ${ }^{22}$ These five isoenzymes were selected from the hitlist due to having published crystal structures and E-values less than $1 \mathrm{e}^{-50}$. Then, a multiple sequence alignment of these six Alrs was performed using Clustal Omega. ${ }^{23}$ The amino acid sequences of these proteins were acquired from Uniprot, a freely accessible resource for protein sequences (Uniprot.org). Protein sources and accession numbers are as follows: E. faecium, I3TYG8; E. faecalis, Q837J0; S. pneumoniae, P0A2W8; G. stearothermophilus, P10724; P. aeruginosa, Q9HTQ2; M. tuberculosis, P9WQA9.

\section{Homology modeling}

The sequence of EF_Alr was retrieved from Uniprot (entry: I3TYG8) and was used as a target for homology modeling using the SWISS-MODEL server. ${ }^{24,25}$ This tool produced a 3D model for the EF_Alr target sequence by searching a library of experimentally determined protein structures from the Protein Data Bank to identify a suitable template. The template was used to perform a target-template sequence alignment which resulted in the generation of the finished model. The highest quality homology model was selected according to two statistical parameters: Global Model Quality Estimation (GMQE) and Qualitative Model Energy Analysis (QMEAN) Z-score. ${ }^{26,27}$ Additionally, the EF_Alr homology model was uploaded to the SAVES server Version 5 to assess the overall stereochemical quality according to PROCHECK. ${ }^{28}$

Comparison of the overall folding of alanine racemases and determination of the active site

The EF_Alr homology model was visualized using UCSF CHIMERA. ${ }^{29}$ The MatchMaker function was used to superimpose the EF_Alr homology model and crystal structure of E. faecalis Alr. ${ }^{30}$ The EF_Alr homology model resulted in a tentative model of the EF_Alr active site containing the PLP cofactor. The FindHBond tool in UCSF CHIMERA was employed to identify putative active site residues involved in catalytic activity and stabilization of the PLP cofactor.

\section{Plasmid construction}

The EF_Alr gene was amplified from E. faecium genomic DNA with standard PCR methods using primers containing the restriction sites for NdeI and XhoI restriction enzymes (Integrated DNA technologies) which are listed in Table 1.

\begin{tabular}{|c|c|}
\hline Primer & Sequence \\
\hline EF_Alr_NdeI_FP & 5'- GGAAGACTAGAAAGAAGGAAAACATATGGT'TGTCGGCT'TGGCACC -3' \\
\hline EF_Alr_XhoI_RP & 5'-CTCCTCT'T'T'T'TACCATAGGACTCGAGTTAT'TCTTGATATTCTCT'TGG -3' \\
\hline
\end{tabular}

The PCR mixture $(50 \mu \mathrm{L})$ was comprised of $1 \mu \mathrm{L}$ of $100 \mathrm{ng} / \mu \mathrm{L}$ template genomic DNA, $25 \mu \mathrm{L}$ of Phusion master mix (2X), 1.5 $\mu \mathrm{L}$ DMSO, $2.5 \mu \mathrm{L}$ of $10 \mu \mathrm{M}$ forward primer, $2.5 \mu \mathrm{L}$ of $10 \mu \mathrm{M}$ reverse primer, $0.5 \mu \mathrm{L}$ of Phusion High fidelity $(2 \mathrm{U} / \mu \mathrm{L})$ enzyme (Thermo Scientific), and $17 \mu \mathrm{L}$ dd $\mathrm{H}_{2} \mathrm{O}$. PCR amplification was performed in a T100 Thermal Cycler (Bio-Rad) at the following parameters: $98{ }^{\circ} \mathrm{C}$ for $10 \mathrm{~s}, 65^{\circ} \mathrm{C}$ for $20 \mathrm{~s}$, and $72{ }^{\circ} \mathrm{C}$ for $30 \mathrm{~s}$, followed by a final extension time of 7 min at $72{ }^{\circ} \mathrm{C}$. Following the manufacturer's protocol, the PCR products were purified by gel extraction (Qiagen). The amplified DNA product was digested with corresponding restriction enzymes (New England Biolabs) before ligation into the pET28b expression vector (Novagen), which was cut by the same enzymes, to form the recombinant plasmid pET28b-EF_Alr.

Enzyme expression and purification

Enzyme EF_Alr was produced in E. coli BL21 (DE3) cells. A standard bacterial culture for large-scale expression consisted of 2 X $1 \mathrm{~L}$ of LB broth medium shaken at $37^{\circ} \mathrm{C}$ until the $\mathrm{OD}_{600}$ reached 0.6. At this absorbance, expression was induced by adding isopropyl- $\beta$-D-thiogalactoside (IPTG) to a final concentration of $0.5 \mathrm{mM}$, after which the culture was incubated for a period of 48 
hours at $20{ }^{\circ} \mathrm{C}$ with shaking. The cells were harvested by centrifugation and dissolved in $20 \mathrm{~mL}$ cold buffer $(20 \mathrm{mM}$ Tris-HCL, $100 \mathrm{mM} \mathrm{NaCl}, \mathrm{pH}$ 8.0). This was followed by the addition of $20 \mu \mathrm{L}$ Halt Protease Inhibitor Cocktail (100x). Sonication was employed to lyse the cells and the lysate was cleared by centrifugation. The supernatant was applied to a 5-mL Bio-Scale Mini Nuvia IMAC column (Bio-Rad) and eluted with a linear gradient $(100 \mathrm{~mL})$ of $250 \mathrm{mM}$ imidazole buffered with $20 \mathrm{mM}$ Tris- $\mathrm{HCl}$ and $100 \mathrm{mM} \mathrm{NaCl}(\mathrm{pH} 8.0)$. Fractions with pure $(>95 \%)$ Alr were collected and dialyzed twice against $20 \mathrm{mM}$ Tris- $\mathrm{HCl}$ and 100 $\mathrm{mM} \mathrm{NaCl}\left(\mathrm{pH}\right.$ 8.0) and then stored at $-80^{\circ} \mathrm{C} .10 \%$ SDS-PAGE analysis was utilized to verify the purity of the EF_Alr fractions.

Determination of ensyme activity at different $p H$ values

EF_Alr activity was determined at eight different $\mathrm{pH}$ values $(6.5-10.5)$ at $30^{\circ} \mathrm{C}$ using $\mathrm{D}$-alanine as the substrate. The activity was measured in the $\mathrm{D}$ - to L-alanine direction by monitoring the production of NADH $\left(\varepsilon_{340}=6.22 \mathrm{mM}^{-1} \mathrm{~cm}^{-1}\right)$ at $340 \mathrm{~nm}$ as L-alanine was converted to pyruvate and ammonia by L-alanine dehydrogenase (Ald) (Scheme 1). The reaction mixture (250 $\mu \mathrm{L}$ ) was comprised of 0.004-16 mM D-alanine (dissolved in buffer), NAD $(906 \mu \mathrm{M})$, Ald $(3.18 \mu \mathrm{M})$, and purified EF_Alr $(0.201 \mu \mathrm{M})$ with an appropriate buffer. Assays corresponding to $\mathrm{pH}$ 6.5-8.5 were performed in sodium monobasic/dibasic phosphate buffers while assays corresponding to $\mathrm{pH} 9-10$ were performed in carbonate/bicarbonate buffers. The data were obtained by triplicate kinetic runs at each $\mathrm{pH}$.

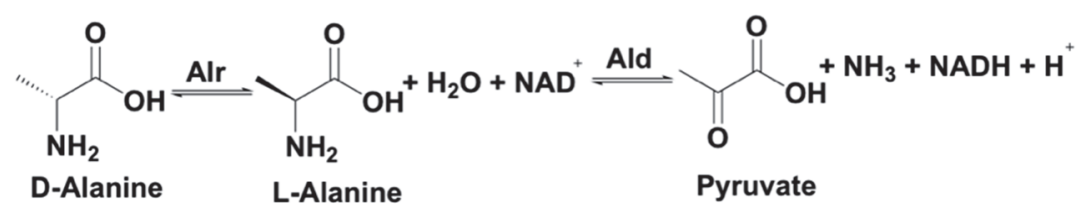

Scheme 1. EF_Alr facilitated isomerization of D-alanine to L-alanine followed by NAD ${ }^{+}$-dependent oxidation of L-alanine to pyruvate in the presence of alanine dehydrogenase (ALD).

\section{RESULTS}

Sequence alignment

Six Alrs from six different bacterial species were aligned based on their amino acid sequences using Clustal Omega (Figure 1). The results from the BLAST analysis are reported in Table 2. The BLAST results and alignment showed there is high sequence similarity among these Alr proteins. Based on the sequence alignment and homology modeling results, we predict that Lys40 and Tyr268 are most likely involved in the alanine racemization reaction by EF_Alr. The regions near these two proposed active site residues were found to have high homology. Additionally, the homology modeling results, and sequence alignment suggest that conserved residues Tyr44, Arg140, His 170, Ser 208, Arg223, Tyr268, and Tyr357 form hydrogen bonds with the PLP cofactor and play a critical role in its stabilization within the active site.

\begin{tabular}{|c|c|c|c|}
\hline Alr Isoenzyme & Maximum Score & E-Value & Percent Identity \\
\hline E. faecalis & 486 & $2 \mathrm{e}^{-172}$ & $63 \%$ \\
\hline S. pneumoniae & 380 & $1 \mathrm{e}^{-130}$ & $52 \%$ \\
\hline G. stearothermophilus & 322 & $6 \mathrm{e}^{-108}$ & $46 \%$ \\
\hline P. aeruginosa & 193 & $4 \mathrm{e}^{-58}$ & $36 \%$ \\
\hline M. tuberculosis & 185 & $1 \mathrm{e}^{-54}$ & $35 \%$ \\
\hline
\end{tabular}

Table 2. Maximum Scores, E-Values, and Percent Identities between EF_Alr and five Alr isoenzymes from BLAST analysis. 
E. faecium

E.faecalis

S. pneumoniae

G.stearothermophilus

$P$. aeruginosa

M. tuberculosis

E. faecium

E. faecalis

S. pneumoniae

G.stearothermophilus

$P$. aeruginosa

M. tuberculosis

E. faecium

E.faecalis

S.pneumoniae

G.stearothermophilus

P. aeruginosa

M. tuberculosis

E. faecium

E.faecalis

S. pneumoniae

G.stearothermophilus

$P$. aeruginosa

M. tuberculosis

E. faecium

E. faecalis

S. pneumoniae

G. stearothermophilus

P. aeruginosa

M. tuberculosis

E. faecium

E. faecalis

S. pneumoniae

G.stearothermophilus

P. aeruginosa

M. tuberculosis

E. faecium

E.faecalis

S. pneumoniae

G.stearothermophilus

P. aeruginosa

M. tuberculosis

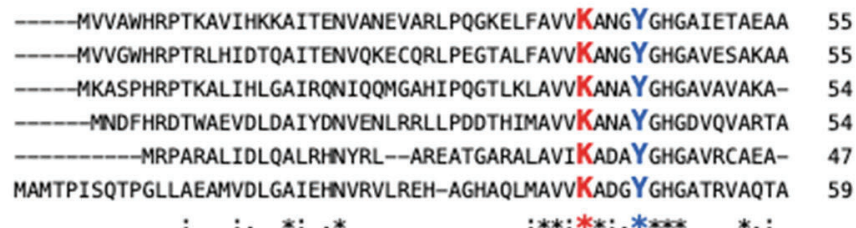

: :. *: .*

:**:***;,$* * * ; * ;$

VAGGASGFCVSNLDEGVELREAGFTQPILILNM-VPYDALTVAVAHDLSVTAGTREWLQA KKGGATGFCVALLDEAIELREAGVQDPILILSV-VDLAYVPLLIQYDLSVTVATQEWLEA IQDDVDGFCVSNIDEAIELRQAGLSKPILILGV-SEIEAVALAKEYDFTLTVAGLEWIQA LEAGASRLAVAFLDEALALREKGIEAPILVLGA-SRPADAALAAQQRIALTVFRSDWLEE LAAEADGFAVACIEEGLELREAGIRQPILLLEGFFEASELELIVAHDFWCV-VHCAWQLE LGAGAAELGVATVDEALALRADGITAPVLAWLH-PPGIDFGPALLADVQVAVSSLRQLDE

$$
\text { . : *: ::*.: ** *. *:* . . }
$$

AAAVLEKSKLETPLSIHLKADTGMGRIGFCTPEEVKEAAAFIK--ESRVLEWEGLFTHFS ALQQLT-PESNTPLRVHLKVDTGMGRIGFLTPEETKQAVRFVQ--SHKEFLWEGIFTHFS LLD---KEVDLTGLTVHLKIDSGMGRIGFREASEVEQAQDLLQ--QHGV-CVEGIFTHFA ASALYS---GPFPIHFHLKMDTGMGRLGVKDEEETKRIVALIE--RHPHFVLEGLYTHFA AIE---RASLARPLNVWLKMDSGMHRVGFFPEDFSA-AHERLR--ASGKVAKIVMMSHFS LLHAV--RRTGRTATVTVKVDTGLNRNGVGPAQFPAMLTALRQAMAEDAVRLRGLMSHMV

$$
\text { . :**:*:**. . . : : : : }
$$

TADQADDTWNLQKERFIEVLKKLPE---LPRYVHVSNSATALWHDETIGNMIRYGVAMY 229 TADEIDTSYFEKQAGRFKAVLAVLEE---LPRYVHVSNSATALWHPDVPGNMIRYGVAMY 228 TADEESDDYFNAQLERFKTILASMKE---VPELVHASNSATTLWHVETIFNAVRMGDAMY 224 TADEVNTDYFSYQYTRFLHMLEWLPS---RPPLVHCANSAASLRFPDRTFNMVRFGIAMY 225 RADELDCPRTEEQLAAFAAASQGL-----EGEISLRNSPAVLGWPKVPSDWVRPGLLY 214 YADKPDDSINDVQAQRFTAFLAQAREQGVRFEVAHLSNSSATMARPDLTFDLVRPGIAVY 236

**: . . * * **: : . : :** :*

GLNPSGHA-LPEVYPLQPALELVSELIQVKKLPAGEGIGYGETYITPEAEWIGTIPIGYA 288 GLNPSGNK-LAPSYALKPALRLTSELIHVKRLAAGEGIGYGETYVTEAEEWIGTVPIGYA 287 GLNPSGAV-LDLPYDLIPALTLESALVHVKTVPAGACMGYGATYQADSEQVIATVPIGYA 283 GLAPSPGIKPLLPYPLKEAFSLHSRLVHVKKLQPGEKVSYGATYTAQTEEWIGTIPIGYA 285 GATPFERA-HPLADRLRPVITLESKVISVRDLPAGEPVGYGARYSTERSQRIGVVAMGYA 273 GLSPVPAL---GDMGLVPAMTVKCAVALVKSIRAGEGVSYGHTWIAPRDTNLALLPIGYA 293

* * * . : : . : *: : * :.** : : :. : :**k*

DGWPRKMQ-GFSLLVEGNYCET IGRVCMDQLMIRLP-QEF--PVGTKVTLIGKNADKEIT 344 DGWLRHLQ-GFTVLVNGKRCEIVGRVCMDQCMIRLA-EEV--PVGSVITLVGKDGNEENT 343 DGWTRDMQ-NFSVLVDGQACPIVGRVSMDQITIRLP-KLY--PLGTKVTLIGSNGDKEIT 339 DGWLRRLQ-HFHVLVDGQKAPIVGRICMDQCMIRLP-GPL--PVGTKVTLIGRQGDEVIS 341 DGYPRHAADGTLVFIDGKPGRLVGRVSMDMLTVDLT-DHPQAGLGSRVELWGPN----VP 328 DGVFRSLGGRLEVLINGRRCPGVGRICMDQFMVDLGPGPLDVAEGDEAILFGPGIRGEPT 353

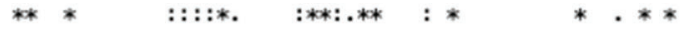

MQDIADQLGTIHYEVACGLGQRIPREYQE--_-_-_ 373 LQMVAEKLETIHYEVACTFSQRIPREYN-_-_-_ 371 ATQVATYRVTINYEVVCLLSDRIPREYY--_-_- 367 IDDVARHLETINYEVPCTISYRVPRIFFRHKRIMEVRNAIGRGESSA 388 VGALAAQFGSIPYQLLCNLK-RVPRVYSGA-_-_-_-- 357 AQDWADLVGTIHYEVTTSPRGRITRTYREAENR--_---- 386

* :**:: *: * :

Figure 1. Multiple sequence alignment of alanine racemase from six different bacterial species. Proposed catalytic residues are shown in red. Proposed residues that form Hydrogen bonds with PLP with an interatomic distance less than $3 \AA$ are shown in blue. Positions with a single, fully conserved residue marked by ( $*$ ). $(:)$ is used to mark positions with conservation between groups of strongly similar properties (approximately equivalent to scoring $>0.5$ in the Gonnet PAM 250 matrix). Sources and protein accession numbers: E. faecium, I3TYG8; E. faecalis, Q837J0; S. pneumoniae, P0A2W8; G. stearothermophilus, P10724; P. aeruginosa, Q9HTQ2; M. tuberculosis, P9WQA9.

Homology modeling

An alignment and homology model for EF_Alr was generated using the SWISS-MODEL server (Figure 2, Table 3). The E. faecalis Alr crystal structure was selected as a suitable template protein structure for the target because it was the only VRE Alr crystal structure available and exhibited high sequence identity (63.34\%) and high coverage (99\% of target EF_Alr aligned to the template). ${ }^{13}$ The GMQE and QMEAN scoring functions were used as the preliminary methods to distinguish between suitable 
and poor models. The high alignment values and GMQE and QMEAN4 values suggested a statistically acceptable model was generated for EF_Alr (Table 3).
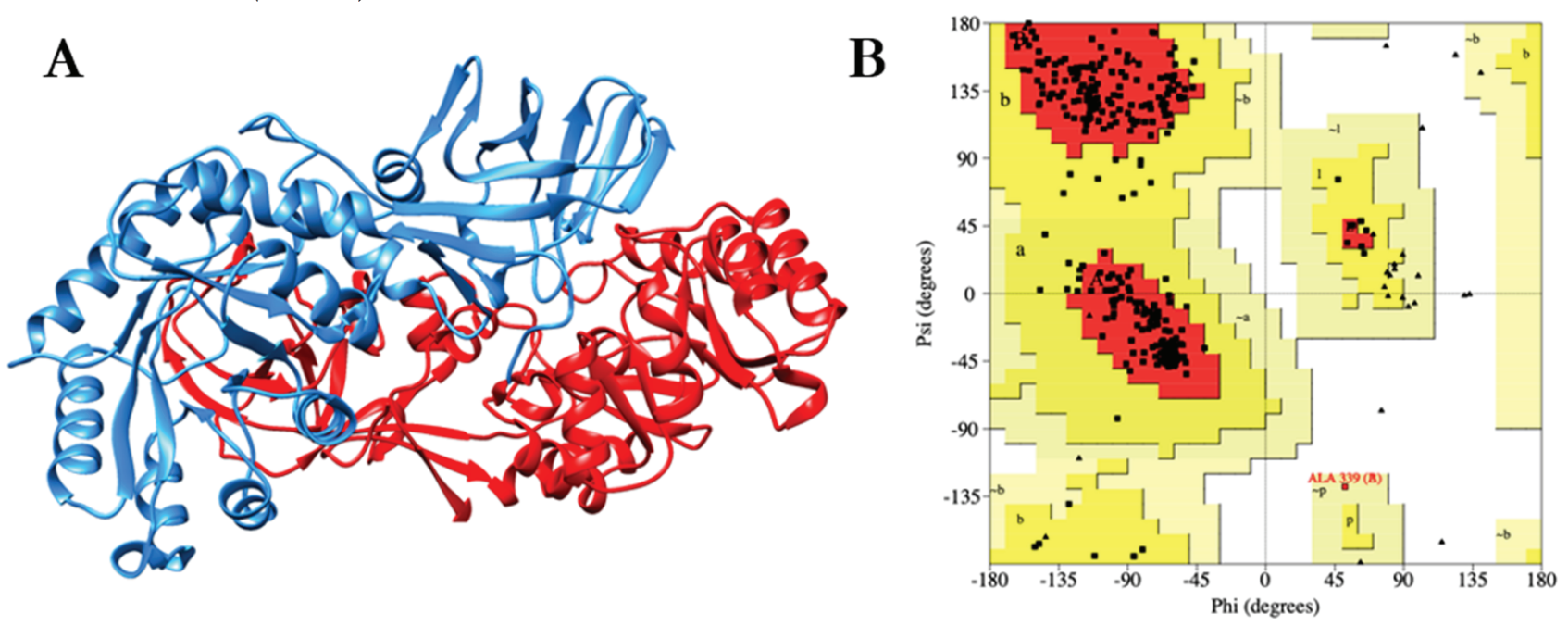

Figure 2. EF_Alr homology model and corresponding Ramachandran plot. (A) EF_Alr homology model produced with SWISS-MODEL that had suitable sequence coverage with the E. faecalis Alr template protein. EF_Alr is a homodimer. Individual chains are represented in blue and red. (B) Ramachandran plot for EF_Alr homology model obtained by PROCHECK, exhibiting dihedral angles Psi and Phi of amino acid residues. The most favored zones are represented by red; additional allowed zones by yellow; generously allowed zones by beige; and white areas are disallowed zones.

\begin{tabular}{|c|c|c|c|c|c|c|c|c|}
\hline $\begin{array}{c}\text { Template } \\
\text { protein }\end{array}$ & $\begin{array}{c}\text { Template } \\
\text { PDB } \\
\text { code }\end{array}$ & $\begin{array}{c}\text { Sequence } \\
\text { Identity }\end{array}$ & GMQE & QMEAN4 & $\begin{array}{c}\text { Most } \\
\text { favored } \\
\text { zones }\end{array}$ & $\begin{array}{c}\text { Additional } \\
\text { allowed } \\
\text { zones }\end{array}$ & $\begin{array}{c}\text { Generously } \\
\text { allowed } \\
\text { zones }\end{array}$ & $\begin{array}{c}\text { Disallowed } \\
\text { zones }\end{array}$ \\
\hline $\begin{array}{c}\text { E. faecalis } \\
\text { Alr }{ }^{13}\end{array}$ & $3 \mathrm{E} 6 \mathrm{E}$ & $63.34 \%$ & 0.83 & -0.80 & $90.5 \%$ & $9.1 \%$ & $0.3 \%$ & $0.0 \%$ \\
\hline
\end{tabular}

Table 3. Summary of E. faecium Alr homology model and statistical validation.

Additionally, the Ramachandran plot for the model provided further confirmation of its acceptability. The results, shown in Figure 2 and Table 3, indicated that 90.5\% of residues in the homology model were within the most favored zones (red), 9.1\% of residues in the homology model were inside the additional allowed zones (yellow), $0.3 \%$ of residues in the homology model were within the generously allowed zones (beige), and $0.0 \%$ of residues in the homology model were within the disallowed zones (white). The results of this analysis revealed the high reliability of the overall stereochemical properties of the generated EF_Alr homology model.

\section{Comparison of the overall folding of alanine racemases and determination of the active site}

Using the MatchMaker tool in UCSF CHIMERA, monomers from the EF_Alr homology model and E. faecalis Alr experimental structure were superimposed to elucidate differences in overall folding, shown in Figure 3.A. The calculated Overall RMSD was found to be $0.426 \AA$ and the Q-score 0.964 for the superposition, indicating that there is significant conservation of overall folding and secondary structure between both structures, including the active site regions. Additionally, the active site of the homology model was analyzed in order to identify the possible catalytic residues, and the residues responsible for stabilizing the PLP cofactor (shown in Figure 3.B). The EF_Alr homology model active site and preceding knowledge of the Alr mechanism, indicated two possible ionizable residues, Tyr268 and Lys40, shown with pink labels in Figure 3.B. Using the FindHBond tool in UCSF CHIMERA, seven residues were identified that formed hydrogen bonds with the PLP cofactor with an interatomic distance less than $3 \AA$ : Tyr44, Arg140, His 170, Ser 208, Arg223, Tyr268, and Tyr357. These residues were all conserved among the different Alrs analyzed in the multiple sequence alignment (Figure 1) and likely function to stabilize the PLP cofactor in the active site. 

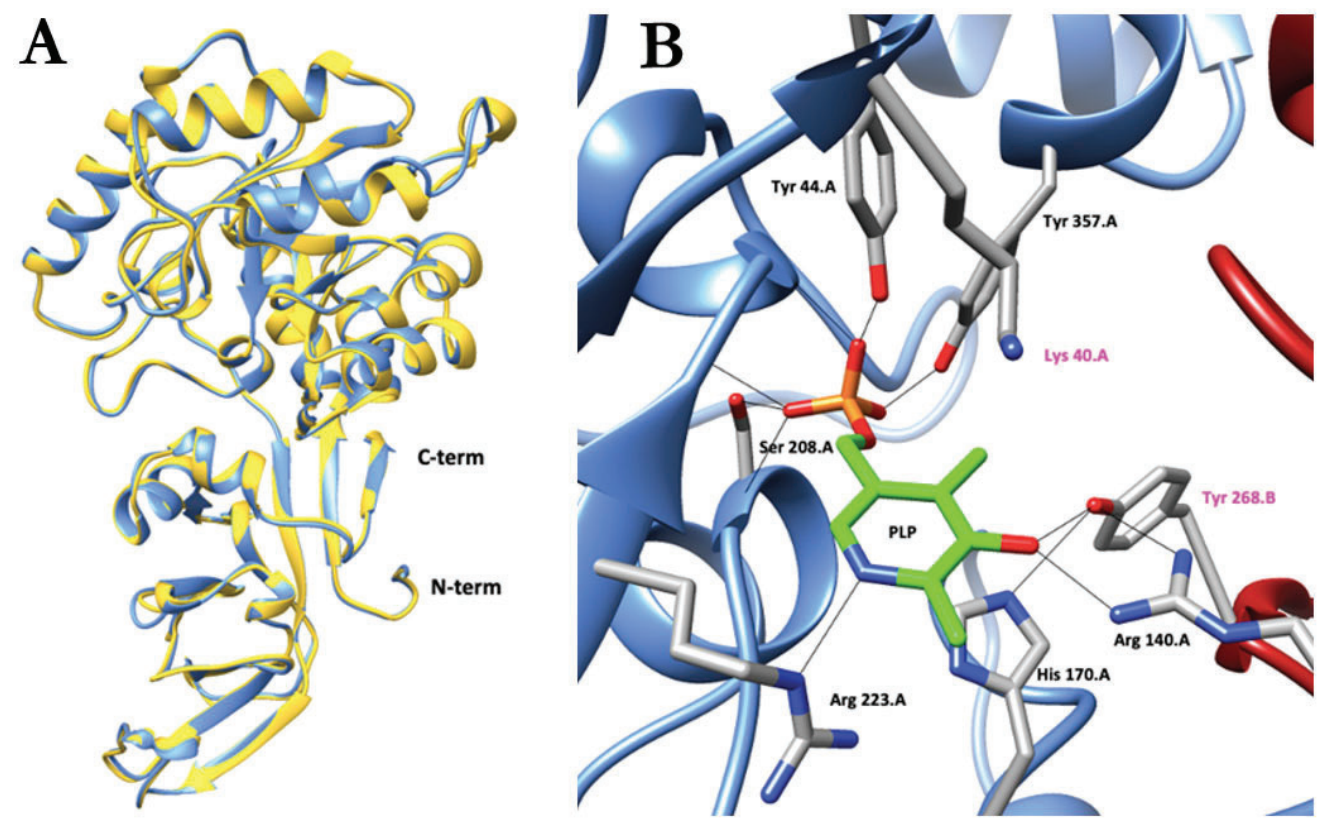

Figure 3. Comparison of the overall folding of Alanine Racemases and visualization of the active site (A) Superposition of EF_Alr monomer with E. faecalis experimental structure monomer. E. faecium Alr homology model monomer shown in yellow. E. faecalis Alr crystal structure monomer shown in blue.13 (B) Proposed active site residues in the EF_Alr homology model. Chain A is shown in blue. Chain B, the partner monomer, is shown in red. Proposed catalytic residues are indicated by pink labels. Hydrogen bonds with an interatomic distance of less than $3.0 \AA$ are depicted by black lines.

\section{Determination of ensyme activity at different $p H$ values}

The EF_Alr was purified by using IMAC Ni-affinity chromatography. EF_Alr purity was confirmed through $10 \%$ SDS-Page (Figure 4). The EF_Alr was found to be banded at approximately $42.8 \mathrm{kD}$, concurring with the theoretical weight of the histagged enzyme. The Michaelis-Menten steady-state kinetic constants were determined by assaying the purified protein from $\mathrm{pH}$ 6.5 to 10.5 using different buffers. A buffer containing $50 \mathrm{mM}$ sodium monobasic/dibasic phosphates and $100 \mathrm{mM} \mathrm{NaCl}$ was used for $\mathrm{pH} 6.5,7,7.5,8$, and 8.5 , and a buffer containing $50 \mathrm{mM}$ sodium carbonate/bicarbonate and $100 \mathrm{mM} \mathrm{NaCl}$ was used for $\mathrm{pH} 9,9.5$, and 10.5. The kinetic data were obtained in triplicate and fitted the Michaelis-Menten equation for each $\mathrm{pH}$ using GraphPad Prism7 to generate the steady-state kinetic constants (GraphPad Software, Inc). A representative Michaelis-Menten plot for $\mathrm{pH} 9$ is shown in Figure 5.A. The steady-state kinetic constants are shown in Table 4. The highest catalytic efficiency, $8.61 \pm 0.5 \mathrm{~s}^{-1} \mathrm{mM}^{-1}$, under experimental conditions was found at a $\mathrm{pH}$ of 9 (Figure 5.B).

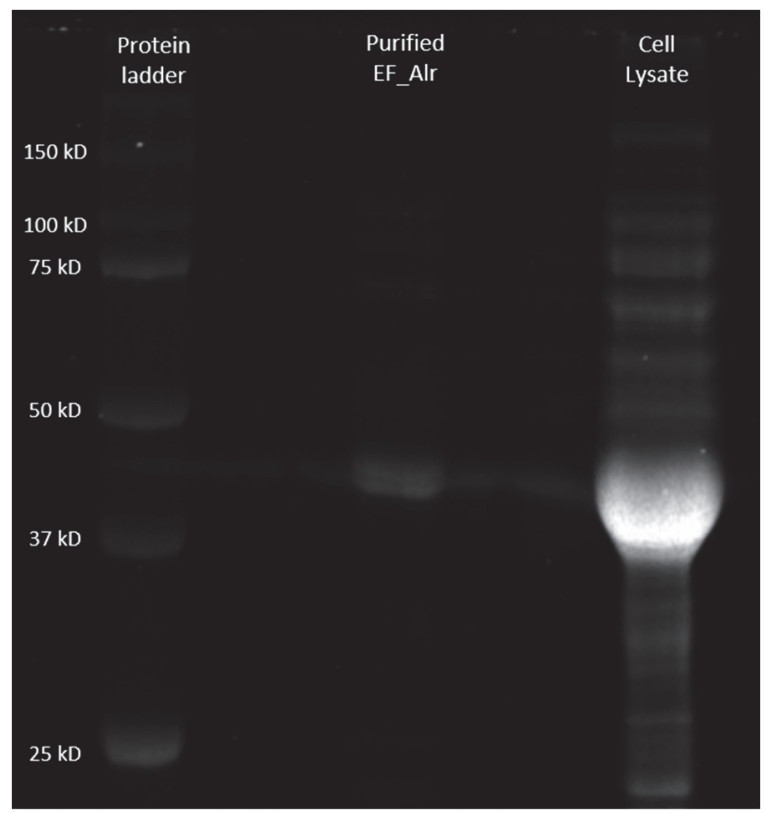

Figure 4. 10\% SDS-PAGE including molecular weight standard (left), purified EF_Alr (42.8 kD) (middle), and lysate before loading Ni-column (right). 


\begin{tabular}{|c|c|c|c|}
\hline $\mathbf{p H}$ & $\boldsymbol{k}_{\text {cat }}\left(\mathbf{s}^{-\mathbf{1}}\right)$ & $\boldsymbol{K}_{\mathrm{m}} \times \mathbf{1 0}^{\mathbf{1}} \mathbf{( m \mathbf { M } )}$ & $\left.\boldsymbol{k}_{\mathrm{cat}} / \boldsymbol{K}_{\mathrm{m}} \mathbf{( s}^{-\mathbf{1}} \mathbf{m} \mathbf{M}^{-\mathbf{1}}\right)$ \\
\hline 6.5 & $2.16 \pm 0.1$ & $12.1 \pm 2$ & $1.79 \pm 0.3$ \\
\hline 7 & $2.29 \pm 0.2$ & $10.4 \pm 4.0$ & $2.20 \pm 0.9$ \\
\hline 7.5 & $5.33 \pm 0.2$ & $9.63 \pm 1$ & $5.53 \pm 0.6$ \\
\hline 8 & $2.98 \pm 0.06$ & $8.62 \pm 0.6$ & $3.46 \pm 0.3$ \\
\hline 8.5 & $7.14 \pm 0.2$ & $8.53 \pm 0.9$ & $8.37 \pm 0.9$ \\
\hline 9 & $6.39 \pm 0.1$ & $7.42 \pm 0.4$ & $8.61 \pm 0.5$ \\
\hline 9.5 & $16.8 \pm 0.5$ & $30.0 \pm 2$ & $5.60 \pm 0.4$ \\
\hline 10.5 & $18.1 \pm 2.0$ & $119 \pm 20$ & $1.52 \pm 0.3$ \\
\hline
\end{tabular}

Table 4. Steady-state kinetic constants for EF_Alr at different $\mathrm{pH}$ values (triplicate). Error represents standard deviation of the mean.
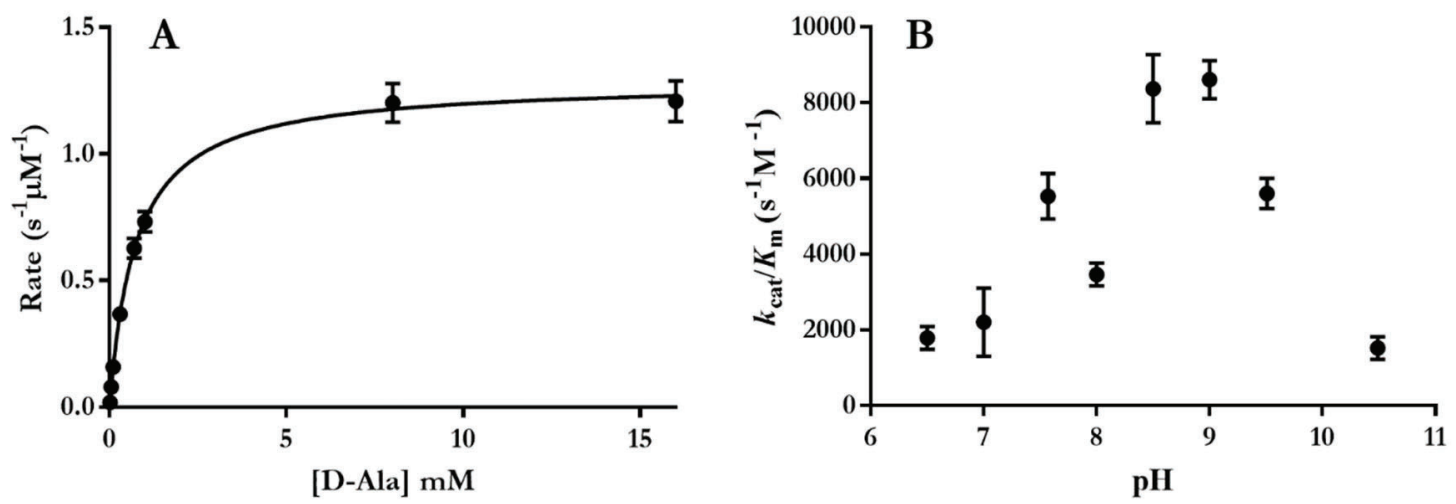

Figure 5. (A) Representative Michaelis-Menten plot for EF_Alr activity at pH 9 (50 mM sodium carbonate/bicarbonate and $100 \mathrm{mM} \mathrm{NaCl}$. Reactions were performed at $30^{\circ} \mathrm{C}$. The steady-state kinetic constants for EF_Alr were determined by fitting the kinetic data (triplicate) to the Michaelis-Menten equation for different $\mathrm{pH}$ values. (B) The $k_{\mathrm{cat}} / K_{\mathrm{m}}$ values were plotted against their corresponding $\mathrm{pH}$ values. Error bars represent standard deviation of the mean.

\section{DISCUSSION}

Due to the development of antibiotic resistance in bacteria there is a persistent need for the development of novel antibiotics. Alr is an appealing antibiotic drug target as it plays a fundamental role in bacteria and is absent in humans, yet the characterization of Alr from multidrug-resistant pathogen E. faecium has not been reported yet. Here we report the characterization of EF_Alr, an essential precondition for employing EF_Alr as a drug target for antibiotic drug development against the pathogenic VRE bacterium E. faceiium. It is not possible to characterize an enzyme in any meaningful way without understanding its optimal $\mathrm{pH}$ conditions. The $\mathrm{pH}$ optimum for EF_Alr was found to be $\mathrm{pH} 9$ while the $\mathrm{pH}$ optimum for Alr from various different bacterial species has been reported in the range of $\mathrm{pH}$ 8.3-10.5 (E. coli [pH 8.3], B. stearothermophilus [ $\mathrm{pH}$ 8.5], S. pneumoniae [8.5], P. putida YZ-26 [pH 9.0], M. tuberculosis [9.0], P. aeruginosa PAOI [pH 10.0], B. pseudofirmus OF4 [pH 10.5]). ${ }^{14-22}$ The maximum kcat/ Km for EF_Alr at $30^{\circ} \mathrm{C}$ was determined to be $8.61 \mathrm{~s}^{-1} \mathrm{mM}^{-1}$, higher than that found for Alr from S. pneumoniae $\left[2.47 \mathrm{~s}^{-1} \mathrm{mM}^{-1}\right]$ and $M$. tuberculosis $\left[1.04 \mathrm{~s}^{-1} \mathrm{mM}^{-1}\right] .{ }^{16,18}$ The wide range in optimal $\mathrm{pH}$ and maximum catalytic efficiencies between Alr from different bacteria further stresses the importance of determining the pH optimum for EF_Alr.

Furthermore, computational methods were used to elucidate characteristics of EF_Alr sequence and structure. A multiplesequence alignment of Alrs from six different bacterial species revealed that EF_Alr shares high sequence homology with other Alrs around the proposed active site residues. In the absence of a crystal structure, an EF_Alr homology model was constructed using the SWISS-MODEL server and served as a starting point for further elucidation of the EF_Alr structure. The model was statistically validated and displayed high stereochemical reliability (Figure 3 and Table 2). By overlaying the EF_Alr homology model with the experimental structure of Alr from E. faecalis, it was observed that both enzymes share exceedingly similar secondary and tertiary structures (Figure 4.A). Additionally, the EF_Alr homology model was used to construct a tentative active site for EF_Alr and identify putative active site residues and the residues that are responsible for stabilization of the PLP cofactor (Figure 4.B).

Previous reports have shown that the Lys40 and Try 268 residues likely function as the catalytic acid and base in the racemization mechanism. This proposed mechanism would start with the formation of a Schiff base connecting PLP to Lys40. The lysine would then be substituted with the alanine substrate before the deprotonated Lys40 (for D-alanine) or deprotonated Tyr268 residue (for L-alanine) abstracts the $\alpha$-hydrogen of the alanine to form a high-energy carbanionic intermediate. The intermediate 
would eventually be protonated from the opposite side by either protonated Lys40 (for L-alanine) or protonated Tyr268 residue (for D-alanine), leading to the enantiomeric product. ${ }^{31-33}$ The above mechanism was proposed based upon the known Alr mechanism for other bacterial species. Further studies need to be performed to validate our mechanistic hypothesis for this alanine racemization by EF_Alr.

As pathogenic bacteria continue to acquire resistance to clinically important antibiotics, research that characterizes antibiotic targets and designs new drugs will remain integral. This work encompasses important structural and kinetic information about alanine racemase from E. faecium that will be necessary for future exploration of novel inhibition strategies and the design of new antibiotics. Known sequence and structure similarities between alanine racemases could be exploited to create a broad-spectrum drug while knowledge of EF_Alr pH optimum and kinetics will be essential when evaluating inhibitory compounds. While the findings reported here could be utilized in many ways, the aim of this work is to build an informational foundation to aid in the development of new antibiotics so that the pathogenic impact of multidrug-resistant E. faecium may be diminished.

\section{ACKNOWLEDGEMENTS}

This work was generously supported by the start-up funding for Dr. Majumdar and Undergraduate Summer Opportunities for Applying Research funding from the Indiana University of Pennsylvania.

\section{REFERENCES}

1. Cetinkaya, Y., Falk, P., and Mayhall, C. G. (2000) Vancomycin-resistant enterococci, Clin Microbiol Rev 13, 4, 686-707. https:// doi.org/10.1128/cmr.13.4.686-707.2000

2. Clewell, D. B. (1990) Movable genetic elements and antibiotic resistance in enterococci, Eur J Clin Microbiol Infect Dis 9, 2, 90 102. https:// doi.org/10.1007/BF01963632

3. Hoge, C. W., Adams, J., Buchanan, B., and Sears, S. D. (1991) Enterococcal bacteremia: to treat or not to treat, a reappraisal, Rev Infect Dis 13, 4, 600-605. https:// doi.org/10.1093/clinids/13.4.600

4. Antibiotic Threats in the United States, 2019, Centers for Disease Control and Prevention, bttps:/ / mww.cdc.gov/drugresistance/ biggest-threats.html (Accessed June 2020)

5. Khodabandeh, M., Mohammadi, M., Abdolsalehi, M. R., Hasannejad-Bibalan, M., Gholami, M., Alvandimanesh, A., Pournajaf, A. \& Rajabnia, R. (2020) High-Level Aminoglycoside Resistance in Enterococcus faecalis and Enterococcus faecium; as a Serious Threat in Hospitals, Infect Disord Drug Targets 20, 2, 223-228. https:// doi.org/ 10.2174/1871526519666181130095954

6. Hidron, A. I., Edwards, J. R., Patel, J., Horan, T. C., Sievert, D. M., Pollock, D. A., and Fridkin, S. K. (2008) NHSN annual update: antimicrobial-resistant pathogens associated with healthcare-associated infections: annual summary of data reported to the National Healthcare Safety Network at the Centers for Disease Control and Prevention, 2006-2007, Infect Control Hosp Epidemiol 29, 11, 996-1011. https:// doi.org/10.1086/591861

7. Meng, L., Qiu, H., Wan, L., Ai, Y., Xue, Z., Guo, Q., Deshpande, R., Zhang, L., Meng, J., Tong, C., Liu, H., and Xiong, L. (2020) Intubation and Ventilation amid the COVID-19 Outbreak: Wuhan's Experience, Anesthesiology 132, 6, 1317-1332. bttps://doi.org/10.1097/aln.0000000000003296

8. Lansbury, L., Lim, B., Baskaran, V., and Lim, W. S. (2020) Co-infections in people with COVID-19: a systematic review and meta-analysis, J Infect 81, 2, 266-275. https:// doi.org/10.1016/j.jinf.2020.05.046

9. Yoshimura, T. and Soda, K. (2007) Alanine Racemase: Structure and Function, Molecular Aspects of Ensyme Catalysis 147-163.

10. Anthony, K. G., Strych, U., Yeung, K. R., Shoen, C. S., Perez, O., Krause, K. L., Cynamon, M. H., Aristoff, P. A., and Koski, R. A. (2011) New classes of alanine racemase inhibitors identified by high-throughput screening show antimicrobial activity against Mycobacterium tuberculosis, PLoS One 6, 5, e20374. https:// doi.org/10.1371/journal.pone.0020374

11. Azam, M. A. and Jayaram, U. (2016) Inhibitors of alanine racemase enzyme: a review, Journal of Ensyme Inbibition and Medicinal Chemistry 31, 4, 517-526. bttps:// doiorg/10.3109/14756366.2015.1050010

12. Wei, Y., Qiu, W., Zhou, X.-D., Zheng, X., Zhang, K.-K., Wang, S.-D., Li, Y.-Q., Cheng, L., Li, J.-Y., Xu, X., and Li, M.-Y. (2016) Alanine racemase is essential for the growth and interspecies competitiveness of Streptococcus mutans, IJOS 8, 4, 231-238. https://doi.org/10.1038/ijos.2016.34

13. Priyadarshi, A., Lee, E. H., Sung, M. W., Nam, K. H., Lee, W. H., Kim, E. E., and Hwang, K. Y. (2009) Structural insights into the alanine racemase from Enterococcus faecalis, Biocbim Biophys Acta 1794, 7, 1030-1040.

bttps:// doi.org/10.1016/j.bbapap.2009.03.006

14. Lambert, M. P. \& Neuhaus, F. C. (1972) Mechanism of D-cycloserine action: alanine racemase from Eschericbia coli W, J Bacteriol 110, 3, 978-987. https:// doi.org/10.1128/JB.110.3.978-987.1972

15. Badet, B., Inagaki, K., Soda, K. \& Walsh, C. T. (1986) Time-dependent inhibition of Bacillus stearothermophilus alanine racemase by (1-aminoethyl) phosphonate isomers by isomerization to noncovalent slowly dissociating enzyme-(1aminoethyl)phosphonate complexes, Biochemistry 25, 11, 3275-3282. https:// doi.org/10.1021/bi00359a029

16. Majumdar, S., Cook, R., Van Wieren, A., and Bond, D. (2018) Kinetic characterization of alanine racemase from Streptococcus pneumoniae, Journal of the Pennsylvania Academy of Science 92, 2, 75-87. 
17. Liu, J. L., Liu, X. Q., and Shi, Y. W. (2012) Expression, purification, and characterization of alanine racemase from Psendomonas putida YZ-26, World J Microbiol Biotechnol 28, 1, 267-274. bttps:/ / doi.org/10.1007/s11274-011-0816-1

18. Cook, R., Barnhart, R., and Majumdar, S. (2019) Effect of $\mathrm{pH}$ on the kinetics of Alanine Racemase from Mycobacterium tuberculosis, Journal of Young Investigators 36, 1.

19. Dong, H., Han, Q., Guo, Y., Ju, J., Wang, S., Yuan, C., Long, W., He, X., Xu, S. \& Li, S. (2018) Enzymatic characterization and crystal structure of biosynthetic alanine racemase from Pseudomonas aeruginosa PAO1, Biochem Biophys Res Commun 503, 4, 2319-2325. bttps:// doi.org/10.1016/j.bbrc.2018.06.155

20. Ju, J., Xu, S., Wen, J., Li, G., Ohnishi, K., Xue, Y., and Ma, Y. (2009) Characterization of endogenous pyridoxal 5'-phosphatedependent alanine racemase from Bacillus pseudofirmus OF4, J Biosci Bioeng 107, 3, 225-229. bttps:// doi.org/10.1016/j.jbiosc.2008.11.005

21. Van Wieren, A., Cook, R. \& Majumdar, S. (2019) Characterization of Alanine Dehydrogenase and Its Effect on Streptomyces coelicolor A3(2) Development in Liquid Culture, J Mol Microbiol Biotechnol 29, 1-6, 57-65. https://doi.org/10.1159/000504709

22. Altschul, S. F., Madden, T. L., Schäffer, A. A., Zhang, J., Zhang, Z., Miller, W., and Lipman, D. J. (1997) Gapped BLAST and PSI-BLAST: a new generation of protein database search programs, Nucleic acids research 25, 17, 3389-3402. https:// doi.org/10.1093/ nar/25.17.3389

23. Sievers, F., Wilm, A., Dineen, D., Gibson, T. J., Karplus, K., Li, W., Lopez, R., McWilliam, H., Remmert, M., Soding, J., Thompson, J. D., and Higgins, D. G. (2011) Fast, scalable generation of high-quality protein multiple sequence alignments using Clustal Omega, Mol Syst Biol 7, 539. https:/ / doi.org/10.1038/msb.2011.75

24. Bordoli, L., Kiefer, F., Arnold, K., Benkert, P., Battey, J., and Schwede, T. (2009) Protein structure homology modeling using SWISS-MODEL workspace, Nat Protoc 4, 1, 1-13. https:/ / doi.org/ 10.1038/ nprot.2008.197

25. Arnold, K., Bordoli, L., Kopp, J., and Schwede, T. (2006) The SWISS-MODEL workspace: a web-based environment for protein structure homology modelling, Bioinformatics 22, 2, 195-201. https://doi.org/10.1093/bioinformatics/bti770

26. Benkert, P., Biasini, M., and Schwede, T. (2010) Toward the estimation of the absolute quality of individual protein structure models, Bioinformatics 27, 3, 343-350. https:// doi.org/10.1093/bioinformatics/btq662

27. Benkert, P., Kunzli, M., and Schwede, T. (2009) QMEAN server for protein model quality estimation, Nucleic Acids Res 37, Web Server issue, W510-514. https:// doi.org/10.1093/nar/gkp322

28. Laskowski, R. A., MacArthur, M. W., Moss, D. S., and Thornton, J. M. (1993) PROCHECK: a program to check the stereochemical quality of protein structures, Journal of Applied Crystallography 26, 2, 283-291.

bttps:// doi.org/10.1107/S0021889892009944

29. Pettersen, E. F., Goddard, T. D., Huang, C. C., Couch, G. S., Greenblatt, D. M., Meng, E. C., and Ferrin, T. E. (2004) UCSF Chimera--a visualization system for exploratory research and analysis, J Comput Chem 25, 13, 1605-1612. https:// doi.org/10.1002/jcc.20084

30. Meng, E. C., Pettersen, E. F., Couch, G. S., Huang, C. C., and Ferrin, T. E. (2006) Tools for integrated sequence-structure analysis with UCSF Chimera, BMC Bioinformatics 7, 339. https:// doi.org/10.1186/1471-2105-7-339

31. Kurokawa, Y., Watanabe, A., Yoshimura, T., Esaki, N., and Soda, K. (1998) Transamination as a side-reaction catalyzed by alanine racemase of Bacillus stearothermophilus, J Biochem 124, 6, 1163-1169. https:// doi.org/10.1093/oxfordjournals.jbchem.a022234

32. Ondrechen, M. J., Briggs, J. M., and McCammon, J. A. (2001) A model for enzyme-substrate interaction in alanine racemase, J Am Chem Soc 123, 12, 2830-2834. https:// doi.org/10.1021/ja0029679

33. Watanabe, A., Yoshimura, T., Mikami, B., Hayashi, H., Kagamiyama, H., and Esaki, N. (2002) Reaction mechanism of alanine racemase from Bacillus stearothermophilus: x-ray crystallographic studies of the enzyme bound with $\mathrm{N}-(5$ 'phosphopyridoxyl)alanine, J Biol Chem 277, 21, 19166-19172. https:// doi.org/ 10.1074/ jbc.M201615200

\section{ABOUT STUDENT AUTHORS}

Arie Van Wieren is a current undergraduate student and plans to graduate from Indiana University of Pennsylvania in the spring of 2021 with a degree in biochemistry. Arie received the Barry M. Goldwater Scholarship in 2020. After graduation, he plans on pursuing an MD/Ph.D. degree in biochemistry.

Emma Bouchard is a current undergraduate student and plans to graduate from Indiana University of Pennsylvania in the spring of 2022 with a degree in biochemistry. After graduation, she plans on pursuing a Ph.D. degree in Chemical and Biomolecular Engineering.

\section{PRESS SUMMARY}

VRE bacterium E. faecium is a pathogen that poses a serious threat to public health as it is often the cause of life-threatening hospital-acquired infections that are difficult to treat with standard antibiotic therapies. In the midst of the COVID-19 pandemic this pathogen is even more concerning, as E. faecium infections are frequently acquired in hospitals through medical devices, such as ventilators. Due to this, there is an urgent need for the development of new antibiotic drugs that can target this pathogen. One possible antibiotic drug target is enzyme alanine racemase (Alr) which is critical to the survival of the bacterium. In this work, the 
activity of Alr from E. faecium (EF_Alr) was characterized and a computational model of the enzyme structure was created. It was determined that EF_Alr has a $\mathrm{pH}$ optimum of $\mathrm{pH}$ 9. The computational model was used to analyze the possible structure and important components of this enzyme. The information reported in this work is the first steps towards the utilization of EF_Alr as an antibiotic drug target that could be used to treat infections from multidrug-resistant E. faecium. 